\title{
SERVIÇO SOCIAL, PROJETO ÉTICO POLÍTICO PROFISSIONAL, PRODUÇÃO DE CONHECIMENTO*
}

\author{
Ana Maria de Vasconcelos \\ Juliana Ferreira Baltar
}

\section{Introdução}

Achados das investigações realizadas no âmbito do NEEPSS (Núcleo de Extensão e Pesquisa em Serviço Social/FSS/UERJ-CNPq/FAPERJ), a partir de dados referentes às respostas dos assistentes sociais às demandas dos trabalhadores/usuários e das requisições institucionais, nos remeteram à necessidade de estudar a produção de conhecimento da área de Serviço Social; produção de vital importância na iluminação dos caminhos de um exercício profissional referenciado pelo projeto ético-político do Serviço Social brasileiro, aqui apreendido na sua vertente anticapitalista crítica (Vasconcelos, 2015).

Diante da vasta produção de conhecimento do Serviço Social em revistas, livros, coletâneas, produções independentes de grupos de pesquisadores ou de profissionais no país, publicações e eventos científicos, TCC, monografias, dissertações e teses dos importantes Programas de Pós Graduação da área, há que se perguntar o porquê das dificuldades sinalizadas pela maioria dos assistentes sociais para pensar e realizar alternativas de prática na direção do projeto ético-político do Serviço Social brasileiro. Ou seja, apesar do Serviço Social se constituir numa área de conhecimento de cariz teórico-metodológico crítico e estabelecer uma interlocução fecunda com intelectuais de áreas afins não capturados pelo pensamento pós-moderno, no cotidiano das atividades socioinstitucionais permanecem históricas contradições, contradições que o projeto profissional veio a lume almejando superar.

Como pode ser apreendido nas justificativas do projeto - como nas Diretrizes Curriculares da ABEPSS -, temos o conhecimento sobre a realidade como instrumento fundamental que, mediando a realidade socioinstitucional, permite uma apropriação crítica e qualificada pelos sujeitos profissionais das necessidades históricas das classes trabalhadoras e das condições e possibilida-

*DOI - 10.29388/978-65-86678-20-8-0-f.181-208 
des socioinstitucionais. São essas mediações que oferecem as condições necessárias a uma prática pensada e avaliada nas suas consequências, fundada em planejamento, construção de estratégias, sistematização, avaliação. Processo dialético exigente que favorece profissionais e equipes consolidarem movimentos/ momentos de ruptura com práticas conservadoras, imediatistas, burocráticas, no enfrentamento do conservadorismo presente na sociedade e, consequentemente, no Serviço Social. Processo de longo prazo, que exige uma conexão qualificada entre espaços de formação e espaços socioinstitucionais, em busca do fortalecimento de práticas mediadas pelo Projeto Ético Político do Serviço Social brasileiro, visto que, para que o conhecimento da realidade se faça instrumento essencial da prática ele deve partir e retornar à realidade, realizando o "caminho de volta".

Ou seja, trata-se de captar a essência e a lógica da atividade [profissional], para retornar a ela como síntese de múltiplas determinações no sentido de negar o que desfavorece, conservar o que favorece o alcance dos objetivos e finalidade das ações, identificar as alternativas não exploradas, oportunidades e possibilidades perdidas, ressaltar suas consequências para instâncias e sujeitos envolvidos, no sentido de, dialeticamente, no processo, elevar a prática níveis superiores (Vasconcelos, 2015, p. 499).

Partindo da dificuldade de alunos e assistentes sociais em sinalizar suas referências teórico-metodológicas e ético políticas, identificada através de pesquisas empíricas realizadas no NEEPSS, neste artigo, daremos destaque a parte do estudo das Teses de Doutorado ${ }^{1}$ publicadas no site da CAPES, entre os anos de 2010 à 2014, que ampliou o estudo dos trabalhos completos publicados nos dois principais eventos científicos do Serviço Social (ENPESS e CBAS) ${ }^{2}$; dos

1 Esta dissertação foi realizada por Juliana Ferreira Baltar, em 2016, no Programa de Pós Graduação em Serviço Social da Universidade do Estado do Rio de Janeiro, intitulada "Serviço Social, Projeto Ético Político e Produção de Conhecimento. Teses de Serviço Social socializadas no banco de dados da CAPES - 2010-2014", e orientada por Ana Maria de Vasconcelos.

${ }^{2}$ Foram realizados estudos acerca das produções constantes dos ANAIS do XII e XIII Congressos Brasileiros de Assistentes Sociais (CBAS), realizados, respectivamente, em 2007 e 2010 (conferir Lima, 2010; Baltar 2012 e Silva, 2013), assim como do XI e XII Encontro Nacional de Pesquisadores em Serviço Social (ENPESS), realizados, respectivamente, em 2008 e 2010 (conferir Silva, 2010 e Borges, 2013). Se já era de se esperar a presença marcante da academia no ENPESS, o que mais nos surpreendeu nos Anais do CBAS foi a presença majoritária de autores vinculados à academia e uma ausência gritante de trabalhos apresentados por assistentes sociais. Assim, foram raros os relatos de experiência ou trabalhos de qualidade fundamentados na realidade vivida 
artigos publicados nas revistas científicas de grande importância para a categoria profissional, tais como ${ }^{3}$, Serviço Social\&Sociedade, Temporalis, Katalyzis, EM PAUTA e do perfil dos Bolsistas de Produtividade/CNPq, da área de Serviço Social ${ }^{4}$.

Objetivamos identificar em que medida a produção analisada faz mediações com o Serviço Social e com o projeto profissional, já que são produções importantes para os assistentes sociais - na formação graduada, pós graduada e formação permanente. Diante dos compromissos assumidos pela categoria com seu projeto profissional, a necessidade de realizar uma prática crítica, criativa, propositiva e avaliada nas suas consequências requer, antes de tudo, segurança de princípios, mas seguida de uma base teórico-metodológica sólida que, em sintonia com aqueles princípios, possibilite superar as representações imediatas na consciência dos sujeitos sobre a realidade, a partir da apreensão do movimento da realidade, através de pesquisas - em diferentes níveis ${ }^{5}$ - voltadas para a apreensão das contradições, possibilidades e alternativas presentes no movimento da realidade.

Os assistentes sociais que, no cotidiano socioinstitucional, dão respostas concretas aos trabalhadores e trabalhadoras através da execução das políticas sociais públicas/privadas e demais serviços socioassistenciais, no contexto da sociedade capitalista (e não só neste momento histórico desta complexa sociedade historicamente destrutiva de homens e mulheres \{destruição material e subjetiva $\}$ e da própria natureza e que, em crise estrutural, mostra flagrantemente sua incapacidade de oferecer felicidade a todos, como prometido), necessitam de uma abordagem qualificada do complexo cotidiano onde estão inseri-

pelos assistentes sociais junto aos usuários.

3 Sobre os estudos das Revistas de Serviço Social de grande circulação no país, conferir: Dória, 2017; Neri, 2016; Rodrigues, 2015; Albuquerque, 2015;

${ }^{4}$ Sobre a pesquisa a respeito do perfil dos bolsistas de produtividade do CNPq da área de Serviço Social, conferir Miranda, 2011.

${ }^{5}$ Aqui estamos nos referindo não só às pesquisas realizadas pelos assistentes sociais/equipes no cotidiano da prática, tendo em vista o planejamento das ações, mas às pesquisas acadêmicas que possam resultar em generalizações, pois é a investigação que fornece condições para apreensão do movimento da realidade. A pesquisa subsidia a construção de propostas por parte dos assistentes sociais, na medida em que estes podem apreender, na realidade, suas contradições, possibilidades e limites, assim como, o conjunto de informações necessárias para o alcance dos objetivos almejados. Assim, o conhecimento adquirido através do estudo da realidade possibilita a construção de uma prática planejada e avaliada nas suas consequências, da mesma forma que pode permitir ao pesquisador, ao tomar o cotidiano da prática sistematizado, a análise teórico-crítica da atividade profissional na expectativa de captar tendências e possibilidades e formular generalizações. Ver Vasconcelos, 2015, Capítulo 2. 
dos. Abordagem que, enfrentando questões complexas e contraditórias colocadas pela atividade profissional, gere conhecimentos qualificados e acessíveis que contribuam com a formação não só dos assistentes sociais, mas de todos os que almejam fortalecer projetos emancipatórios, inclusive os próprios trabalhadores usuários. É desse modo que a categoria poderá contar com uma produção de conhecimento qualificada, não só sobre temáticas da área de fundamentos mas, como podemos apreender nas Diretrizes Curriculares para o curso de Serviço Social da ABEPSS (1996), uma produção sustentada no tripé dos conhecimentos constituídos pelos núcleos de fundamentação da formação profissional, quais sejam: - Núcleo de fundamentos teórico-metodológicos da vida social; Núcleo de fundamentos da formação sócio-histórica da sociedade brasileira; Núcleo de fundamentos do trabalho profissional, que compreende todos os elementos constitutivos do Serviço Social como uma especialização do trabalho. E a ABEPSS reafirma: não se admite "tratamento classificatório, nem autonomia e subsequência entre os núcleos, [que expressam], ao contrário, diferentes níveis de apreensão da realidade social e profissional, subsidiando a intervenção do Serviço Social".

Ora, a ausência de produção qualificada referente ao Núcleo de Fundamentos do Trabalho Profissional é uma questão candente identificada, entre outros, por Iamamoto em tempos remotos e reafirmada em 2007, quando a autora ressalta que

No lapso das duas últimas décadas a restrita, mas, fecunda literatura profissional no âmbito da renovação crítica do Serviço Social voltada aos fundamentos do Serviço Social - em suas dimensões históricas, teóricometodológicas e éticas - tratou, sob diferentes ângulos, da natureza particular da profissão na divisão social e técnica do trabalho e sua dimensão ética.[...] Entretanto, a análise do processamento do trabalho do Assistente Social não adquiriu centralidade e nem foi totalizado nas suas múltiplas determinações, estabelecendo-se uma frágil associação entre os fundamentos do Serviço Social e o trabalho profissional cotidiano, uma vez que este abrange um conjunto de mediações que não foram alvo privilegiado da referida produção (IAMAMOTO, 2007, p. 213-214).

Assim, não surpreende que em diferentes áreas de atuação, observa-se uma manifestação recorrente entre os assistentes sociais: "a academia está distante da prática profissional”. Por outro lado, a escolha destes profissionais para a realização de cursos de especialização e aperfeiçoamento tem se dado, preferencialmente, fora da área do Serviço Social, como cursos de Terapia de Famí- 
lia, Gestão de Projetos, Responsabilidade Social etc. ${ }^{6}$ Cursos que, abandonando a perspectiva de totalidade, priorizam fragmentos da realidade, em busca de respostas ao "que fazer?", na sua totalidade, distantes, quando não em flagrante contradição com as referências ético-políticas e teórico-metodológicas do projeto profissional.

Nos parece que, além de uma frágil produção no que se refere aos fundamentos do trabalho profissional, o conjunto de conhecimentos e habilidades que compõem os núcleos não são tematizados a partir do movimento da realidade profissional, resultando que a categoria não conta com experiências submetidas à análise teórico-crítica que possam revelar não só os limites da atuação profissional, mas alternativas não aproveitadas, oportunidades perdidas, possibilidades de prática presentes no cotidiano profissional etc. Ora, somente uma produção calcada na realidade profissional, ou seja, que acompanhe o frenético movimento da realidade institucional/profissional, pode conter condições de iluminar a formulação e execução de propostas concretas, por parte de assistentes sociais/equipes, que objetivem fortalecer o processo de mobilização, organização e formação de trabalhadores e trabalhadoras, o que, ao mesmo tempo, contribui para que o enriquecimento da produção de conhecimento da área de Serviço Social favoreça a materialização do Projeto Profissional, na nossa concepção, reafirmando, aqui apreendido como projeto anticapitalista crítico.

Como mostram os estudos do NEEPSS, a produção de conhecimento analisada prioriza, em sua maioria, uma abordagem analítica em detrimento de uma abordagem, também, propositiva dos temas que se relacionam com o Serviço Social e com o Projeto Ético-político. Um quadro que certamente dificulta ainda mais a materialização do Projeto Profissional, tendo em vista que fica a cargo dos assistentes sociais inseridos nos diversos espaços sócio ocupacionais realizarem as mediações necessárias da complexa produção de conhecimento da área com a contexto institucional/profissão, em busca de identificar possibilidades de atuação presentes na realidade ${ }^{7}$. Como afirmado em 2015,

[...] há uma grande diferença entre favorecer a formaşão de um intelectual, dentre eles o assistente social, (o que exige tanto apropriação crítica [uma

6 Entre os motivos para não participar das pesquisas realizadas pelo NEEPSS, os assistentes sociais alegam "falta de retorno da academia para os desafios enfrentados no cotidiano", já que as pesquisas representam apenas "críticas ao trabalho profissional executado".

${ }^{7}$ É o que vem sendo sinalizado pelos assistentes sociais, na atualidade, na pesquisa em profundidade realizada no NEEPSS com os assistentes sociais inseridos na política de assistência social (CRAS; CREAS, CentrosPOP), do Município do Rio de Janeiro. 
apropriação que envolve acessar saber acumulado/fazer a crítica desse conhecimento], como produção crítica de conhecimento em consonância com os princípios e objetivos do projeto profissional) e formar e alimentar assistentes sociais ao longo do cotidiano profissional (o que exige — para além da apropriação e produção crítica de conhecimento em consonância com os princípios e objetivos do projeto profissional e tematizar o que "pode/deve ser" — , submeter ao conhecimento e crítica o exercício profissional histórico, tendo em vista "avanços teóricos e técnico-operativos”). Esse é o processo que vai permitir a categoria profissional apreender tanto as consequências da atividade profissional, quanto as possibilidades que a realidade contém, resultando numa produção de conhecimento que dialeticamente forme e ilumine os assistentes sociais no cotidiano da prática. O conhecimento ilumina, mas sem base na realidade perdemos o movimento dos assistentes sociais na história e, consequentemente, o Serviço Social na história. O conhecimento instrui, esclarece, ilustra, mas é a realidade que informa (VASCONCELOS, 2015, p. 259).

No complexo cotidiano da prática, os assistentes sociais, além da ampliação da apropriação dos conhecimentos da área de fundamentos, estão permanentemente desafiados a planejar e executar ações em resposta às demandas dos trabalhadores e às requisições institucionais. Ora, tendo em vista o compromis so com os trabalhadores, este processo exige ainda uma articulação - direta e indireta ${ }^{8}$-com movimentos sociais e / ou com organismos de representação dos diferentes segmentos da classe trabalhadora que realmente enfrentem suas necessidades, demandas e interesses, aí sim, apreendidos como necessidades sociais, demandas e interesses coletivos, rumo à eliminação das desigualdades e à superação da sociedade capitalista. Neste sentido, é que o conhecimento aqui é preciso, estrito na sua forma de servir de instrumento de planejamento estratégico, definição de objetivos, prioridades, táticas, em linha direta com as necessárias e interessadas respostas dos assistentes sociais às classes trabalhadoras.

\footnotetext{
${ }^{8}$ Articulação indireta no sentido de, em meio à atividade sócio assistencial, conectar usuários trabalhadores com movimentos sociais e/ou diferentes organismos que verdadeiramente os represente. Uma tarefa que põe mais uma tarefa para a categoria que é a identificação desses organismos, para referenciar os assistentes sociais, no nível local, regional e nacional.
} 


\section{As Teses de Doutorado da área de Serviço Social publicadas no Banco de Teses e Dissertações da CAPES/2010 e 2014}

$\mathrm{Na}$ perspectiva do Projeto profissional, a produção de uma tese de doutorado é de fundamental importância para o conjunto da produção de conhecimento da área Serviço Social, exatamente pelo seu caráter de originalidade e amadurecimento teórico, como expressão do tempo de dedicação que o pesquisador emprega; das condições dadas na construção de uma tese; das condições ideais de debate e qualificado da produção, etc. São teses de importantes Programas de Pós-Graduação inscritos na área de Serviço Social na CAPES, que produzem conhecimento para uma área específica, através do desenvolvimento de suas linhas de pesquisa, das publicações do seu corpo docente e das pesquisas realizadas por seus docentes, mestrandos e doutorandos. Resultando em publicações diversas - livros, capítulos ou artigos -, essas teses tornam-se referência na graduação, pós-graduação e na categoria profissional como um todo, constituindo importante contribuição, tanto para a consolidação da área de conhecimento, como na busca de alternativas de materialização do projeto profissional, no contexto da sociedade do capital.

Foram analisadas $114^{9}$ Teses de Doutorado defendidas entre os anos de 2010-2014, que se encontram publicadas no Banco de Teses e Dissertações da CAPES. A análise se deu a partir dos resumos, sumários, introduções, considerações finais e referências bibliográficas, por vezes, exigindo consulta na íntegra.

As teses dão uma grande contribuição à produção de conhecimento da área de Serviço Social e das áreas das Ciências Humanas e Sociais, a partir de estudos que tomam como objeto central o Estado, a Sociedade, a Questão Social, as Políticas Sociais etc. $\mathrm{Na}$ sua construção, os autores se apropriam do conhecimento disponível sobre seu objeto de estudo, em diferentes áreas de co-

\footnotetext{
${ }^{9}$ Consultadas diferentes plataformas, o número real de teses de doutorado na área de Serviço Social publicadas no período estudado foi 372 teses. Porém, entendendo a importância do site da CAPES como referência para a comunidade científica do país e do mundo, foram analisadas as 114 teses encontradas neste site. Ou seja, foram analisadas $31 \%$ do total de teses publicadas no período, sendo este um número considerado respeitável no âmbito das ciências estatísticas, para uma amostragem. Não podemos deixar de sinalizar, que este achado da investigação - menos de $1 / 3$ das teses constando do Banco de Teses -, certamente põe um desafio e uma tarefa para a representação do Serviço Social na CAPES. Ressaltamos que todas as porcentagens consideram a totalidade das teses analisadas.
} 
nhecimento, sendo $57 \%$ assistentes sociais e $43 \%$ profissionais de outras áreas do conhecimento.

Quanto a presença do Serviço Social, das 114 Teses, 59\% fazem alguma menção ao Serviço Social, enquanto $41 \%$ não realizavam nenhum tipo de menção ao Serviço Social. Se a maioria das teses realiza algum tipo de menção ao Serviço Social, por vezes, isto se dá através de uma única manifestação como: "este estudo é importante para o Serviço Social", sem que o autor mos trasse a razão dessa importância. Sem dúvida, a menção ao Serviço Social, mesmo que rarefeita, favorece a consolidação do Serviço Social como área de conhecimento na CAPES e estímulo ao conjunto de docentes e discentes nos diferentes espaços e níveis de formação.

Quanto aos doutores que fazem referência ao Serviço Social, dentre as 114 teses $^{10}$ analisadas, temos: $44 \%$ dos assistentes sociais estabelecem algum tipo de mediação com o Serviço Social, enquanto 15\% não citam o Serviço Social; $13 \%$ dos doutores não assistentes sociais fazem alguma referência à profissão, mesmo que seja uma referência abstrata, sem aprofundamento das razões dessa afirmação, enquanto $24 \%$ não estabelecem nenhum tipo de mediação da sua produção com o serviço social.

Embora 44\% dos assistentes sociais façam alguma referência ao Serviço Social, quando a análise do texto é aprofundada, observa-se que, em sua maioria, as referências à profissão não se dão de forma substantiva ${ }^{11}$, mas de forma abstrata ${ }^{12}$ - calcadas em um dever ser sem base na realidade em movi-

${ }^{10} \mathrm{Em} \mathrm{4 \%}$ das teses não foi possível identificar as mediações com a profissão.

11 As teses foram analisadas a partir de "Eixo de Análise" construído no âmbito do NEEPSS, objetivando o estudo da produção de conhecimento da área. Em resumo, como substantivas, consideramos as produções em que os autores, ao longo do texto, se esforçam para garantir que sua produção sirva de instrumento estratégico para uma prática pensada e avaliada nas suas consequências. Assim, fazendo mediações com a profissão/ exercício profissional, sinalizam alternativas, possibilidades, limites, o porquê da importância do tema para a profissão e para os profissionais; o porquê da importância dos assistentes sociais acessarem tais conhecimentos, informações, instrumentos etc.; ou seja, dados de realidade se põem de forma explícita. Quanto ao projeto profissional, é considerada relação substantiva quando, no corpo do texto, os princípios e as diretrizes do projeto são citados de forma coerente e articulada. Assim, constituem discussões de temas concernentes ao cotidiano profissional, desenvolvidas em todo corpo do texto, a partir de uma articulação tanto analítica quanto propositiva, nas quais o Serviço Social e o projeto profissional atravessam, de forma pluralista e sem ecletismos, toda a tese.

12 Quanto às mediações com o Serviço Social e o projeto profissional, as teses em que os autores anunciam a importância do texto para a profissão e seu compromisso com o projeto do Serviço Social, mas sem revelar dados de realidade que identifique esse 
mento. Assim, fica ausente um conteúdo que, para além do Núcleo de Fundamentos, fundamente os assistentes sociais no embate com o complexo cotidiano da prática.

É importante demarcar que se dos doutores não assistentes sociais que procuram a área de Serviço Social para seu doutoramento - procura quase sempre creditada ao interesse pelo pensamento crítico social - podemos contar com importantes contribuições para a área de conhecimento Serviço Social, não se deve esperar deles uma produção relacionada ao Núcleo de Fundamentos do trabalho profissional, o que se já diminui a contribuição que a área pode dar ao exercício profissional ${ }^{13}$. De mais a mais, não só pela qualidade da educação fundamental e pela sua condição discente, os estudantes de Serviço Social, como parte e expressão de segmentos diferenciados da classe trabalhadora - cada vez mais um segmento pauperizado - não possuem uma bagagem teórico-cultural necessária para se apropriarem criticamente dos conteúdos teórico-metodológicos e ético políticos necessários à formação graduada e permanente daquele intelectual necessário à materialização do projeto profissional ${ }^{14}$, o que desafia

compromisso/importância foram identificados como relação abstrata com o projeto. Não confundir abstrato com abstração: "capacidade intelectiva que permite extrair da sua contextualidade determinada (de uma totalidade) um elemento, isolá-lo, examiná-lo. Para mais detalhes sobre essa diferenciação, consultar Vasconcelos, 2015 e Netto, 2009 13 Isso não quer dizer que não sejam necessárias mediações com a profissão essencialmente no contexto das disciplinas que ministram - por parte daqueles docentes/pesquisadores que se propõem e formar assistentes sociais na graduação e na pós-graduação. Uma realidade que se torna cada vez mais difícil de garantir, visto que, quando ocupam cadeiras docentes em Escolas de Serviço Social, esses docentes costumam dar prosseguimento a seus estudos, sem espaço para problematizar sua presença e seu papel de educador na área de Serviço Social.Os eventos de Iniciação Científica de alunos das faculdades de Serviço Social no país revelam, em parte, isso, quando observamos trabalhos realizados por alunos de Serviço Social - e aqui registrese, tanto orientados por professores assistentes sociais como professores de outras áreas - que poderiam ser incorporados por qualquer unidade dos Centros de Ciências Sociais e Humanas. Assim, tanto sua produção como as disciplinas que ministram deixam a cargo dos estudantes, o que inclui os assistentes sociais da pós-graduação, a realização das mediações com a profissão o que, no caso dos estudantes de graduação, ficam restritas ao Estágio Curricular Obrigatório. Desse modo, não fica difícil entender porque esses alunos, como profissionais, passem a vocalizar o mantra presente na profissão: na prática a teoria é outra.

14 "Na medida em que não interessa ao capitalismo que "seus" intelectuais se questionem sobre os fundamentos do sistema, sua lógica e suas consequências, não há interesse dos dominantes na formação de um intelectual que, "habilitado para operar numa área particular, compreenda o sentido social da ação e a significância da área trabalhada no conjunto da questão social" (Netto, 1996), o que se põe como exigência de uma formação generalista - teórico-metodológica, ético-política e técnico-operativa. A formação 
mais ainda a academia na criação das condições necessárias a uma análise social fundada na crítica da economia política, por parte dos graduandos, base da materialização do projeto profissional.

No contexto de uma formação graduada e de um exercício profissional que não exercita a análise teórico-crítica do que vem sendo realizado pelos assistentes sociais, pergunta-se como o aluno no contexto do Estagio Curricular e como os assistentes sociais terão condições de garantir uma sistematização qualificada da experiência profissional que tenha condições de ser submetida a uma análise teórico-crítica que possibilite negar, conservar, redefinir e/ou redirecionar os caminhos da prática, seja no planejamento, na gestão e/ou na execução terminal dos serviços socioassistenciais - públicos ou privados?

A falta de mediações com o Serviço Social e com o projeto profissional de um grande número de teses - mediações que envolvam os desafios, as possibilidades e os limites impostos aos profissionais no cotidiano da prática -, certamente vem resultando em prejuízos na sua apropriação crítica e propositiva pelo conjunto da categoria profissional, principalmente diante do seu crescimento exponencial alavancado pelo ensino privado e pelos cursos à distância, no contexto de uma realidade que se apresenta de forma fragmentada, desarticulada, envolvida por concepções do senso comum, em relação estreita com a moral da sociedade burguesa.

Como afirmado em 2015:

Entendemos que a pesquisa e a produção de conhecimento no Serviço Social, quando da apreensão do movimento do real, para além de formar o pesquisador/profissional/intelectual/cientista, têm como objetivo, como afirmava Marx, influir na transformação do mundo. Assim, não se trata de apropriação do conhecimento pelos políticos visando boas políticas, nem pelos profissionais visando boas práticas - ainda que nesse exercício, a teoria possa favorecer práticas compromissadas com os trabalhadores. O fundamental é que a teoria seja apropriada pelas massas tendo em vista realimentar a luta social na busca da emancipação de todos. Lembremos o que afirma Marx: a teoria se transforma em força material quando apropriada pelas massas. (Vasconcelos, 2015, p. 554, nota 14.

centrada em competências, bem ao gosto do "Acordo de Bolonha"/União Europeia abril de 2009, que vem pautando as reformas universitárias em todo o mundo, só cobra pela competência antecipada e adquirida, muito aquém da formação daquele "homem completo, pleno", o que requer um intelectual, sujeito consciente e participante ativo da vida pública (Vasconcelos, 2015, p. 21, nota 15). 
Ora, na impossibilidade de exercício das mediações entre teoria-realidade-exercício que exige ser iniciado na graduação -, dificilmente o futuro profis sional terá condições de avançar nas mediações necessárias a uma prática pensada, tendo em vista não só o planejamento daquilo que realiza, mas, fundamentalmente, a democratização de conhecimentos e informações necessários e relevantes com os trabalhadores-trabalhadoras/usuários, no seu processo de formação, mobilização e organização para a luta pela superação do capital, o que, certamente, está condicionado à qualidade do espaço profissional resultante das atividades de planejamento. Assim, diante da qualidade da formação graduada e permanente e da complexidade da realidade, podemos realizar prognósticos sobre a direção da prática dos assistentes sociais, mas só a análise concreta de situações concretas relativas ao cotidiano do exercício profissional, porque saturadas de muitas determinações, pode apreender a direção social que a prática profissional vem tomando, suas tendências e reais consequências, mas, principalmente, no que diz respeito à atenção prestada diretamente aos usuários, apreender as possibilidades e alternativas de práticas contidas na realidade (Vasconcelos, 2015).

Como já afirmava Netto em 1989, "sem considerar as práticas dos assistentes sociais, a tradição marxista pode deixar escapar elementos significativos da vida social - as práticas dos assistentes sociais frequentemente incidem sobre processos que, tratados pelo referencial teórico-metodológico de Marx, oferecem insumos para a sua verificação e enriquecimento. (NETTO, 1989, p. 101)". Ora, como mostram os estudos realizados no NEEPSS, grande parte do que é colocado como possibilidade teórica/“dever ser" na direção do projeto profissional não tem como base o cotidiano profissional dos assistentes sociais na atualidade. Com isso, não queremos dizer que toda a produção de conhecimento da área de Serviço Social tenha de estabelecer mediações com a profissão; trata-se de sinalizar a escassez e a debilidade das produções que referenciam os assistentes sociais tendo em vista consolidar ações profissionais mediadas pelo projeto profissional; produções que, tomando a realidade socioassistencial como objeto de atenção, possibilite aos intelectuais que têm como função desenvolver e enriquecer a produção de conhecimento da área assumir "sua responsabilidade social", o que abrange seu papel frente ao "problema da intervenção social e de como resolvê-lo" (Coutinho, 2006, p. 114).

Diríamos que, diante desses problemas que atingem todos os intelectuais, para os assistentes sociais, não se trata apenas da necessária e essencial participação em partido político e organizações, mas de encontrar meios 
de atuar na busca de respostas a um Serviço Social mediado pelo projeto profissional, o que requer colocar como objeto de investigação o combate empreendido e os desafios enfrentados pelas massas trabalhadoras no cotidiano da vida e, consequentemente, pelos assistentes sociais \{como trabalhadores que são $\}$ no cotidiano da prática, onde vige a encarniçada luta de classes. É deste modo que, através da produção de conhecimento e do exercício profissional, que o assistente social poderá dar sua contribuição na organização da sociedade e na luta "pela hegemonia política e ideológica da classe ou bloco de classes com os quais se identifica". Como afirma [Coutinho], é condição para a retomada de uma batalha pela hegemonia que os intelectuais - entendidos na ampla acepção que lhes atribui Gramsci [o que nos leva a considerar todos os assistentes sociais e não só os que exercem sua função junto à academia/docência/ pesquisa] — voltem a desempenhar suas funções públicas. (Vasconcelos, 2015, p. 265)

Certamente, a falta de mediações de grande parte da produção de conhecimento da área com o próprio Serviço Social está favorecendo o conservadorismo e desfavorecendo o projeto profissional, visto que, para além das dificuldades na formação graduada e permanente, os assistentes sociais estão sob uma lógica de trabalho precarizada, com a obrigatoriedade de atingir metas, operar a burocracia do sistema, etc, isto é, em condições de trabalho desfavoráveis, como é próprio do conjunto dos trabalhadores, o que amplia os obstáculos na busca de garantir investimentos necessários a um exercício profissional crítico que rompa com ações conservadoras e burocráticas e caminhe na direção dos objetivos vocalizados de "defesa da classe trabalhadora".

No mais, resta relevante sinalizar mais alguns dados das teses analisadas buscando fundamentar nossa análise.

Quanto ao caráter das mediações com a profissão, excetuando os 41\% que não fazem mediações com a profissão, predominam as teses identificadas como "Analíticas"15/ 36\% [11\% Analítico/Pesquisa Documental mais 25\% Analítico/Pesquisa Documental e de Campo), seguidas das teses "Analítico/ Propositivas"/23\%(7\% Analítico/ Propositivas/Pesquisa Documental, mais 16\% Analítico/Propositivo / Pesquisa Documental e de Campo).

Em comparação com a produção dos congressos e revistas analisados no NEEPSS, as produções de cunho Analítico/Propositivo contaram com pequeno incremento. Ainda que a análise das teses consideradas analítico-proposi-

15 São teses que realizam somente a análise do tema escolhido, podendo se dar a partir de revisão bibliográfica e/ou abordagem/discussão teórica de um tema. 
tivas não tenha se dado a partir da consideração dos textos na sua totalidade, observou-se que as proposições com relação ao Serviço Social giram em torno do "dever ser", com indicação de ações para a construção das políticas sociais e de mudanças na postura do Estado, da Sociedade e dos Movimentos Sociais, sem mediações com a complexidade do cotidiano profissional, seus desafios, limites e possibilidades e com o Projeto profissional. Na medida em que são deixadas a cargo do leitor - assistentes sociais e discentes - a realização das mediações necessárias com o frenético cotidiano profissional, certamente essas teses - ou artigos que as sintetizam - deixam de subsidiar os assistentes sociais inseridos nas áreas objeto de estudo da tese e nas demais áreas.

Podemos afirmar assim, que não encontramos teses que diante da indissociabilidade das dimensões teórico-metodológica, ético política e técnicooperativa, tomam como base o complexo cotidiano profissional dos assistentes sociais junto aos usuários e enfrentem os desafios que esse cotidiano põe à categoria profissional. Assim, a partir dos nossos estudos, afirmamos que o "Por que fazer", "O que fazer", "Como fazer", "Para que fazer”, o que dá vida à unidade teoria-prática, é algo que está quase ausente da produção de conhecimento na área de Serviço Social, na atualidade. Desse modo, os assistentes sociais brasileiros - e os assistentes sociais que tomam o projeto do Serviço Social como referência em outros países - não contam com uma bibliografia qualificada que revele como a presença da análise social fundada na crítica da economia política no cotidiano profissional pode fazer e/ou está fazendo a diferença nas respostas profissionais às demandas dos trabalhadores/usuários e às requisições institucionais.

E aqui, os que assumem o projeto profissional como referência, não estamos somente deixando "escapar elementos significativos da vida social" que as práticas dos assistentes sociais oferecem como insumos para a sua verificação e enriquecimento, como afirma Netto (1989, p. 101), mas deixando de trazer à tona possibilidades concretas de materialização do projeto profissional no contexto da sociedade do capital, o que certamente tem contribuído para que parte dos assistentes sociais, cada vez mais significativa, desacredite na ciência como instrumento fundamental na luta pela emancipação humana. Assim, a partir de uma produção de conhecimento que realiza indicações para a prática sem base na complexa e contraditória realidade vivida pelos profissionais, um conjunto expressivo de assistentes sociais vêm afirmando o projeto profissional como utópico. Nos parece que afirmar as possibilidades de práticas mediadas pelo projeto profissional 
[...] não se trata de uma profissão de fé no projeto do Serviço Social e, consequentemente e muito menos, no projeto de sociedade ao qual este projeto está articulado. Com base na realidade, ou seja, a partir da abstração da processualidade real, trata-se de uma defesa assentada na história da humanidade que mostra como homens e mulheres foram capazes de, diante de possibilidades apreendidas na realidade e de suas consequências dialéticas, revolucionar sua própria história no enfrentamento de diferentes tipos de adversidades. Afinal, quantos dos frutos dessas revoluções, em tempos idos, não foram considerados utopia e quantas coisas permanecerão utópicas até serem transformadas em realidade pelos homens e mulheres? (Vasconcelos, 2015, p.73)

Mas se é assim, a abstração da processualidade real é um processo his tórico, contínuo, que só pode dar seguimento à afirmação das possibilidades de materialização do projeto profissional quando a produção de conhecimento da área revelar teoricamente como os assistentes sociais, diante das possibilidades presentes na realidade e das suas consequências dialéticas, "revolucionar"/ou não o cotidiano profissional, no enfrentamento dos desafios e limites impostos ao exercício profissional. Ou seja, a categoria profissional não tem de onde esperar uma produção qualificada que aborde teoricamente as possibilidades de práticas mediadas pelo projeto profissional, a não ser da produção qualificada da área de Serviço Social, o que coloca os assistentes sociais envolvidos nessa produção de conhecimento diante da difícil tarefa que é responder pela produção qualificada na área de fundamentos, e que não vem sendo produzida pelas demais áreas afins na direção do projeto profissional, e pela produção que qualifique a prática profissional.

Como afirma Netto (2009, p. 693), "a pesquisa é indispensável ao Serviço Social se a profissão quiser se manter com um estatuto efetivamente universitário" o que resultou em "um segmento dedicado expressamente à pesquisa". Ora se cabe a cada assistente social/equipe desenvolver uma atitude investigativa no cotidiano profissional, tendo em vista "acompanhar os avanços dos conhecimentos pertinentes ao seu campo de trabalho [e] conhecer concretamente a realidade da sua área particular de trabalho", é o exercício sistemático da pesquisa que pode possibilitar avanços teóricos e técnico-operativos necessários à formação graduada e permanente da categoria profissional e ao exercício profissional (Vasconcelos, 2015, p. 258).

Fica claro também que a questão não é a produção de conhecimento da área do Serviço Social tomar este ou aquele objeto de estudo. O que se des- 
taca é a ausência de um debate qualificado sobre o movimento dos assistentes sociais junto aos trabalhadores e trabalhadores/usuários que possa sinalizar as possibilidades reais de materialização do projeto profissional, como vocalizado em toda a história de construção e consolidação do movimento de ruptura dos assistentes sociais com práticas conservadoras ${ }^{16}$. Assim,

Com a análise concreta de situações concretas ${ }^{17}$, trata-se de desobscurecer, identificar e submeter à análise teórico-crítica o que está sendo feito \{pelos assistentes sociais/equipes\}, como, para que, com que e em que condições, tendo em vista apreender as consequências das ações profissionais no favorecimento ou não dos trabalhadores/usuários, como indicado no projeto profissional e, nesse movimento/processo, negar (no sentido dialético) práticas que não favoreçam; fortalecer e divulgar as que favorecem; redirecionar as ações; identificar lacunas nos estudos, nos levantamentos, no planejamento; demarcar lacunas, fraturas, contradições e falhas no acúmulo teórico e técnico-operativo do profissional/equipe que coordena a atividade e contradições frente às referências ético-políticas assumidas; indicar questões relevantes a serem investigadas em profundidade etc. etc. (Vasconcelos, 2015, p. 271)

Quanto às temáticas abordadas nas teses analisadas, a questão central não é a sua fragmentação, tanto entre as que mencionam o Serviço Social, como as que não mencionam ${ }^{18}$. A questão central, e que necessita de estudos mais aprofundados, é o tratamento dos temas. Abandonado a perspectiva de totalidade - mesmo que por vezes reivindicada -, os autores se afastam da direção social defendida pelo projeto profissional, o que pode tornar ainda mais complexa a apropriação destas produções pela massa da categoria profissional.

\footnotetext{
${ }^{16} \mathrm{E}$ que fique claro que aqui não se trata de fabricar manuais e/ou regras do que fazer ou não fazer nas diferentes áreas de atuação profissional, nos moldes do que encontramos na vasta literatura do Serviço Social tradicional e que ainda referencia assistentes sociais no cotidiano da prática. Como sinalizou uma assistente social em pesquisa realizada no final da década de 1990 (Vasconcelos, 2002), o que certamente ainda podemos identificar na atualidade - em tempos de ensino privado e EAD -, "tenho Iamamoto com referência para estudar Serviço Social e Balbina Otoni Vieira para fazer Serviço Social".

${ }^{17}$ Para aprofundamento desse debate, ver Vasconcelos, 2015, Capítulo 3.

${ }^{18}$ Indicamos, a seguir, entre as 114 , o número de teses a partir das temáticas mais presentes, das que mencionam o Serviço Social e das que não mencionam, respectivamente: Prática e formação profissional: 13-0; Assistência Social: 13-4; Educação:7-7; Gênero, geração, raça, etnia: 8-5; Questão agraria/ movimentos sociais: 9-4; Saúde (diferentes níveis e especialidades): 4-9; Outros temas: 13- 18. Total de 67 teses que mencionam o Serviço Social e 47 que não mencionam.
} 
Como já sinalizado, com o crescimento exponencial da categoria nos anos 2000 - a maioria formada no ensino privado/EAD -, se já era difícil a apropriação da produção da área pela massa dos assistentes sociais, isto torna um problema grave nos anos 2000, na medida em que, a ausência de mediações necessárias da produção de conhecimento com o Serviço Social é potencializada por uma formação que não vem permitindo a apreensão das contradições presentes em uma produção em que os autores, mesmo reivindicando a referência ético política e teórico-metodológica do projeto profissional, vocalizam não só valores, mas uma abordagem teórico-metodológica em contradição com o projeto. ${ }^{19}$

É fato que um conjunto expressivo de assistentes sociais, ao mesmo tempo em que vocalizam o projeto do Serviço Social como referência, sinalizam sua aversão a Marx e ao marxismo. Sem condições de aprofundar essa questão aqui ${ }^{20}$, é necessário ressaltar que "foi em Marx e no marxismo que os sujeitos do projeto profissional, no seu nascedouro, foram buscar suas referências". Ora, na medida em que "[...] a estrutura de nossa sociedade, ao mesmo tempo em que põe o ser social como ser de relações, no mesmo instante e pelo mesmo processo, oculta a natureza dessas relações ao observador" (Netto, 1995), é "somente em Marx podemos ter acesso à teoria social que forneceu/ fornece instrumentos para a crítica da ordem burguesa a partir do método materialista histórico e dialético, da teoria do valor trabalho e da perspectiva da revolução ${ }^{21}$ (Vasconcelos, 2015, p.17)”.

Diante dos dados que estamos analisando nos perguntamos se quem está inserido em um espaço privilegiado para produzir conhecimento (a Universidade) não está e/ou não consegue, sem ecletismos, realizar as mediações necessárias de sua produção com o Serviço Social, como esperar que os assistentes sociais inseridos no frenético cotidiano dos espaços sócio ocupacionais -

\footnotetext{
19 Uma situação agravada pelo fato de um contingente expressivo de assistentes sociais indicar que tudo o que vem da academia e "verdade", passando a ser reproduzido sem crítica; questão observada, não só nas pesquisas do NEEPSS com assistentes sociais, mas entre discentes de graduação e pós.

20 Ver Vasconcelos, 2015, Preludio)

${ }^{21}$ O que não quer dizer que o debate de ideias não seja fundamental. A questão central é não confundir pluralismo com ecletismo, ao conciliar pontos de vista inconciliáveis. "Diante da direção social que afirmamos e do entendimento que temos do projeto profissional, torna-se essencial esclarecer que pluralismo é, frequentemente, confundido com ecletismo - ou seja, com a convivência entre perspectivas ético-políticas e teórico-metodológicas incompatíveis - , ou utilizado para uma crítica velada ao projeto profissional. Aqui, a garantia do pluralismo é entendida como uma abertura do projeto profissional a valores e teorias não colidentes com suas finalidades" (Ver Vasconcelos, 2015, p.184, nota 106).
} 
pressionados por péssimas condições de trabalho, metas inalcançáveis, estressados diante do sofrimento de uma população usuária atingida pelo desemprego, doenças, negação de direitos possam fazê-lo? Como poderão usufruir de uma produção de conhecimento da área de Serviço Social que muitas vezes é difícil de ser digerida até por intelectuais de áreas afins, no frutífero debate possibilitado pela produção de assistentes sociais? Como poderão construir as condições para exercitar as necessárias mediações teoria-realidade que as próprias unidades de ensino que tomam o projeto de formação da ABEPSS têm dificuldade de promover? Ora, se quem está inserido em um espaço privilegiado para produzir conhecimento - as universidades públicas, às quais estão articulados a quase totalidade dos Programas de Pós-Graduação de todas as áreas de conhecimento, além de raras PUCs)- não está e/ou não consegue realizar as mediações necessárias da produção de conhecimento com o Serviço Social, isso, certamente, está repercutindo na categoria como um todo, desde a graduação. Isso nos leva a reafirmar, a partir dos achados e das análises produzidas no âmbito do NEEPSS, que:

[...] as possibilidades de prática contidas na realidade objeto da ação profissional, [...] só podem ser apreendidas a partir de uma leitura crítica dessa realidade, fruto de relações e conexões sistemáticas e necessárias - ainda não existentes - entre as atividades profissionais e o que está garantido como direitos sociais e, no caso dos assistentes sociais, os princípios e referências do projeto ético-político do Serviço Social brasileiro. Frequentemente os assistentes sociais vocalizam e/ou viabilizam propostas heterônomas - determinadas por gestores ou outros profissionais - não apontando ou propondo as ações necessárias a serem realizadas a partir de análise da realidade (Vasconcelos, 2000, p. 8).

É no contexto da vocalização de propostas heterônomas pelos assistentes sociais, considerando a totalidade das teses analisadas e observando a qualidade da relação das teses com o Serviço Social, que identificamos 30\% dos doutores fazendo menção ao Serviço Social de forma abstrata, formal, sem nenhuma argumentação e $29 \%$ dos doutores realizando mediações substantivas com a profissão. Considerando o número de teses identificadas como abstratas somadas às teses que não mencionam o Serviço Social (41\%), temos $71 \%$ das teses na área de Serviço Social que não estabelecem mediações substantivas com a profissão. Por outro lado, 37\% das teses que fazem menção ao Serviço Social citam o projeto como referência, enquanto que, $22 \%$,embora citem o Serviço Social, não consideram o projeto como referência para análise. Das te- 
ses que citam o Projeto do Serviço Social (37\%), 22\% o citam de forma explícita, referenciando os princípios e as referências teóricas que o constituem e 15\% o citam de forma implícita, ou seja, é na leitura do texto que foram identificados princípios e valores presentes no projeto; $26 \%$ promovem uma relação substantiva com o projeto profissional e $11 \%$ uma relação abstrata.

Importante ressaltar que, mesmo nas teses em que os autores fazem mediações com o projeto profissional de forma substantiva, na maioria não foram identificadas referências ao "que fazer", "como fazer", "para que fazer", consequências para os trabalhadores etc.; ou seja, não avançam em formulações estratégicas com base na realidade profissional, tendo em vista contribuições na superação de práticas conservadoras, burocráticas, imediatistas.

Alguns dados relacionados ao perfil dos doutores em Serviço Social favorecem a análise: $57 \%$ possui graduação em Serviço Social, cursada em instituições públicas (63\%); 48\% realizaram seus cursos de mestrado em Serviço Social, $68 \%$ cursados em instituições públicas; $43 \%$ são graduados em outras áreas; $80 \%$ dos doutores são docentes (47\% exercendo somente docência; 15\% articulando docência com pesquisa; $14 \%$ com atividade socioinstitucional; e $4 \%$ as 3 modalidades).

Considerando que o Serviço Social, na realidade social, política, econômica e cultural, é chamado pelo Estado/burguesia, como profissão, para, prioritariamente, atuar no controle dos trabalhadores e trabalhadoras, em confronto direto com as finalidades do projeto profissional, o que impõe aos assistentes sociais compromissados com este projeto um processo de formação (graduada e permanente) extremamente exigente, o número de profissionais que busca qualificação para atuar junto aos trabalhadores e trabalhadoras é ínfimo (2\%), mesmo somando os docentes que realizam atividades de pesquisa e socioinstitucionais (4\%). Mas, não podemos nos esquecer que o critério utilizado nas seleções das pós-graduações no país prioriza a formação para a atividade docente, sendo poucos os assistentes sociais que conseguem furar este bloqueio. Ao mesmo tempo, como já indicado na literatura, como a direção social da pósgraduação em Serviço Social no país tem favorecido que outras categorias profissionais busquem a qualificação na área de Serviço Social, isto pode contribuir para que profissionais de áreas afins tomem como referência o projeto do Serviço Social em busca de condições de estruturação de um trabalho voltado para o atendimento das reais demandas da classe trabalhadora.

O fato da maioria (80\%) dos doutores exercer atividade docente - $51 \%$ em Serviço Social, muitas das vezes realizando seu doutoramento nas unidades em que trabalham -, nos leva à hipótese de que a própria formação graduada e 
pós graduada em Serviço Social também está condicionada ao não exercício das mediações necessárias dos conteúdos das disciplinas de fundamentos com o Serviço Social, com o projeto profissional e com a realidade em movimento. Ou seja, o Serviço Social, o projeto profissional e o cotidiano profissional tendem a ficar na sombra no ensino do Serviço Social, sendo que essa tarefa fica relegada à disciplina de Estágio Curricular e/ou ao próprio Estágio Supervisionado/supervisor, como tem revelado os alunos em formação (Vasconcelos et al., 2013).

Pesquisa de longo prazo, realizada pelo NEEPSS, com alunos de uma das grandes universidades públicas do Rio de Janeiro, que tem seu Currículo Pleno e projeto pedagógico para a formação e capacitação dos futuros assistentes sociais referenciados pelo Projeto Ético Político do Serviço Social brasileiro, vem revelando que os estudantes têm dificuldades em apreender a lógica do Projeto Profissional nas suas dimensões ético-políticas e teórico-metodológicas, ainda que afirmem o projeto como referência. O que mostra que a simples inserção dos alunos nos espaços da universidade pública e de qualidade pode não contribuir para a formação do intelectual que possa, no exercício profissional, seja nas atividades sócioassistenciais, na docência, na gestão e na pesquisa - formular e operar práticas mediadas pelo projeto profissional. (Vasconcelos et al., 2011, p. 09).

Isso revela que se faz cada vez mais necessário que a categoria se volte para uma produção de conhecimento que também aborde o Serviço Social, já que a maioria da produção de conhecimento da área de Serviço Social - no caso aqui trabalhado, conhecimento elaborado por pesquisadores que fazem parte do restrito grupo de assistentes sociais que produz conhecimento de ponta para a área de conhecimento Serviço Social/ Grande Área das Ciências Sociais Aplicadas, tal como descrito pela CAPES - não vem conseguindo estabelecer as mediações necessárias com o Serviço Social na direção de dar materialidade ao Projeto Ético Político do Serviço Social brasileiro.

Como pode ser apreendido nas Diretrizes Curriculares da ABEPSS (1996), dentre tantas outras indicações, é necessário que a formação (graduada e permanente) possa dar condições para que o discente/profissional tenha consciência dos rebatimentos das formas de exploração dos trabalhadores no capitalismo nas condições de vida e trabalho da classe trabalhadora, sendo estes rebatimentos, que se expressam nas diferentes expressões da questão social, objeto da atividade profissional. Ou seja, sem que a compreensão da lógica e das leis fundamentais do capitalismo possa mediar as condições de exploração vivenciadas pela classe trabalhadora, incidindo diretamente nas condições de vida e de 
trabalho, dificilmente o discente/profissional pode ter a noção da necessária segurança de princípios e finalidades e da consequente e exigente competência teórico-metodológica fundada na crítica da economia política, requerida para o estudo/pesquisa da realidade profissional, como condição para planejar, formular e operar estratégias que favoreçam o processo de superação do conservadorismo presente na sociedade e, consequentemente, no Serviço Social, o que nos leva, em maioria, a favorecer as requisições institucionais em detrimento do fortalecimento do processo de formação/mobilização/organização mediando a atenção às necessidades individuais e coletivas operada através das políticas sociais públicas e privadas. (Vasconcelos, 2015).

$\mathrm{Na}$ realidade, profissionais e estudantes de Serviço Social, mesmo se posicionando politicamente em defesa dos interesses dos usuários dos serviços públicos, não conseguem materializar esse direcionamento no trato com os usuários e na defesa do que é público, não só diante da fragilidade teóricometodológica e técnico-operativa, mas, fundamentalmente, da fragilidade éticopolítica, que se expressa na insegurança quanto aos princípios contidos no projeto profissional; princípios que determinam as referências teórico-metodológicas necessárias à sua materialização.

Um quadro que dificulta a apreensão das possibilidades de práticas contidas no movimento de realização das políticas sociais, de modo que, alunos/profissionais não conseguem diferenciar os princípios e valores profissionais - constantes do projeto do Serviço Social -, dos legitimados na sociedade burguesa e que são apropriados pelos indivíduos, no seu processo de socialização, mesmo à sua revelia, assim como mediam as políticas que operamos. As possibilidades dessa diferenciação, que vão nos acompanhar ao longo da nossa vida profissional - afinal vivemos e sofremos os rebatimentos da sociedade do capital, o que temos de enfrentar enquanto essa sociedade existir e que não mostra tendências de ser superada nem no médio nem longo prazo - estão as sentadas também na apropriação do conhecimento produzido socialmente, na área de Serviço Social e em áreas afins.

Enfim, é da produção de conhecimento da área de Serviço Social que a categoria pode esperar reflexões qualificadas que favoreçam as mediações necessárias teoria/realidade na análise das particularidades da profissão tendo em vista formar assistentes sociais na direção do projeto do Serviço Social. E isso não quer dizer, como indica Iamamoto (2008), o retorno de uma perspectiva endógena da profissão, o que foi rompido no processo de ruptura com o conservadorismo. É a submissão das respostas profissionais à análise teórico-critica que contém as possibilidades de qualificá-las nos seus fundamentos históricos, 
metodológicos, éticos e técnico-operativos, como ressalta a autora.

\section{Considerações Finais}

Sintetizamos aqui estudos realizados no âmbito do NEEPSS/FSS/ UERJ sobre a produção de conhecimento da área de Serviço Social. Ao analisarmos as principais revistas científicas da área de Serviço Social, os trabalhos completos dos anais do CBAS e ENPESS e, em especial, as teses da área publicadas no site da CAPES, podemos observar que a produção de conhecimento que referencia a formação e a prática dos assistentes sociais, apesar de grande parte vocalizar a direção social do projeto profissional, vem revelando uma frágil ou nula articulação com a profissão e quando ela acontece é uma abordagem analítica em detrimento de uma abordagem também propositiva, no que se refere à materialização do projeto profissional junto aos trabalhadores usuários nos espaços socioassistenciais.

Assim, reafirmamos o que vem sendo apreendido em nossos estudos: a produção de conhecimento da área de Serviço Social, em sua maioria, não aborda a profissão, o projeto e nem o cotidiano profissional e quando o faz, não prioriza abordagens que favoreçam a estruturação de práticas mediadas pelo projeto profissional - ou seja, práticas que, expressando o compromisso com os interesses e necessidades dos trabalhadores/trabalhadoras/usuários, nos espaços socioinstitucionais, os favoreça na luta pela emancipação humana. A questão não é a qualidade da produção como um todo, principalmente a que aborda os fundamentos da vida social e da sociedade brasileira e que dá a direção do debate na área, mas ressaltar que a produção já analisada revela uma escassa e débil produção que aborda os fundamentos do trabalho profissional e que possa referenciar os assistentes sociais na busca de consolidar a prática dos assistentes sociais mediada pelo projeto profissional.

Se a complexa sociedade capitalista, tendo em vista sua superação, só pode ser enfrentada a partir de análise teórica-critica da realidade, apreendida em seu movimento, numa perspectiva de totalidade, é necessário ao assistente social - profissional que necessita de exigente formação graduada e permanente, para ir além do atendimento às requisições institucionais e demandas espontâneas e emergenciais dos trabalhadores/usuários - um conhecimento teórico ge$\mathrm{ral} /$ generalista, mas também um conhecimento que considere questões relevantes/contraditórias/conflitivas que emergem do movimento do cotidiano da prática, a fim de apreender a realidade em movimento, o que pode lhe permitir, 
a partir de planejamento ${ }^{22}$ - em articulação indissociável com as pautas essenciais da classe trabalhadora na luta pela emancipação humana -, formular e operar estratégias de ação que, desmistificando o que está aparente na realidade, ilumine o exercício profissional - tanto para si, como para os trabalhadores/usuários. Somente assim - como assistentes sociais comprometidos com o projeto profissional e em sintonia de princípios/finalidades/referências teórico-metodológicas -, terão a possibilidade de apreender as necessidades e interesses individuais como necessidade s e interesses sociais, coletivos, dos diferentes segmentos da classe trabalhadora.

Nesse processo, a unidade academia e espaços socioinstitucionais é imprescindível para que a academia, como sujeito profissional banhado pela realidade - social, institucional, profissional - tenha condições de acesso a uma reconstrução empírica qualificada do cotidiano profissional, em condições de ser submetida à análise teórico-crítica, para apreender dialeticamente realidade em seu movimento contraditório, alimentando e realimentando a produção de conhecimento e, consequentemente os sujeitos profissionais. Uma escolha estratégica no contexto do projeto do Serviço Social, tendo em vista o enfrentamento dos desafios e possibilidades presentes no cotidiano profissional, o que, reiterando, contribui tanto para a produção qualificada da área de Serviço Social como para a qualificação e autoqualificação (formação permanente) da massa da categoria profissional, na direção do Projeto do Serviço Social, tendo em vista ir além da simples execução, coordenação, gestão das políticas sociais; um processo dialético de alimentação-realimentação dos sujeitos profissionais, tendo em vista avançar na superação das contradições e dos empecilhos presentes na materialização do projeto profissional no contexto da sociedade do capital.

$\mathrm{Na}$ investigação da realidade está dada a possibilidade do aprimoramento do acervo literário já desenvolvido pela ciência, expandindo-o cada vez mais e dando condições para que o conhecimento teórico adquirido possa, cada vez mais, iluminar a compreensão da realidade e subsidiar a construção de propostas que visem a satisfação das necessidades humanas e sociais - conhecer para transformar. Por isso, ao exercício profissional é necessária uma rigorosa fundamentação teórica em movimento, pois a ação sem teoria é um fazer realizado de acordo com o senso comum; é um fazer que recusa a indissociabilidade teoriaprática.

No cotidiano da prática - política, docente, socioassistencial - o assistente social está em contato com totalidades mais ou menos complexas da realidade social. Estas necessitam de mediações que possibilitem práticas conscien-

${ }^{22}$ Ver Vasconcelos, 2015, Capítulo 1 e 3. 
tes das possibilidades contidas na realidade e suas consequências, processo que só pode ser operado/apreendido teoricamente. Assim, é o necessário conhecimento teórico da realidade em movimento, permeada por concepções e valores burgueses, em confronto com o projeto, que pode possibilitar que o profissional tenha condições de oferecer respostas profissionais que confrontem valores e concepções dominantes, burocráticas, conservadoras, fragmentadores da realidade

O frenético movimento da sociedade do capital nos põe requisições que se tornam cada vez mais complexas diante das péssimas condições de trabalho que atingem a massa dos trabalhadores no capitalismo brasileiro - sociedade mais complexa que a humanidade constituiu ao longo da sua história -, com seus contratos precários, espaços profissionais sucateados, flexibilização dos direitos dos trabalhadores, alinhamento da mais-valia relativa com a maisvalia absoluta etc. e que atingem diretamente os assistentes sociais. É notório que diante das condições de vida e de trabalho dos diferentes segmentos da classe trabalhadora - de onde se originam os futuros assistentes sociais - aumenta a possibilidade de desarticulação entre o que se pretende na atividade profissional e o que de fato é realizado no embate com a realidade. Uma realidade que, como reitera Iamamoto em 2007, não vem sendo objeto de atenção da produção de conhecimento da área de Serviço Social.

Ressaltamos que, com a criação dos Grupos Temáticos de Pesquisa (GTPs) pela ABEPSS ${ }^{23}$, os quais articulam pesquisadores de todo o país e mantêm encontros e Relatórios atualizados, pudemos notar uma diferença em termos de publicação de coletâneas e artigos abordando o Serviço Social e o projeto profissional, produção que necessita de investigação, tendo em vista o cotejamento da análise com os achados da investigação que estamos abordando.

É importante reiterar que a questão central que pontuamos aqui - o que vale para a produção de conhecimento da área e, consequentemente, para as Teses de Doutorado analisadas -, está relacionada ao fato de que na produção de conhecimento que foi objeto de análise no NEEPSS, identificamos raríssimas produções que, numa perspectiva de totalidade e sem ecletismos, to-

\footnotetext{
${ }^{23}$ A ABEPSS possui sete GTPs, são eles: “Trabalho, Questão Social e Serviço Social”, "Política Social e Serviço Social", "Serviço Social: Fundamentos, Formação e Trabalho Profissional Movimentos Sociais e Serviço Social”, "Questões Agrária, Urbana, Ambiental e Serviço Social”, "Serviço Social, Relações de Exploração/Opressão de Gênero", "Raça/Etnia, Geração, Sexualidades" e "Ética, Direitos Humanos e Serviço Social". No endereço a seguir, podemos encontrar os Relatórios dos GTPs atualizados. http://www.abepss.org.br/noticias/confiraosrelatoriosdosgruposdetrabalhodepesquisal gtp)daabepss-100.
} 
mam a realidade profissional como objeto de atenção, tendo em vista cumprir o papel da produção de conhecimento da área de Serviço Social em dar respostas à busca de transformar em realidade aquilo que é afirmado teoricamente pelo projeto profissional e constante da produção de conhecimento qualificada que dá a direção do debate na profissão: a possibilidade de materialização do projeto profissional na sociedade do capital, tendo em vista favorecer trabalhadores e trabalhadoras, para além do acesso a políticas e serviços, nos seus processos de formação, mobilização e organização para a luta pela emancipação humana.

Diante disso, podemos afirmar que os assistentes sociais não estão contando com uma produção de conhecimento qualificada - pautada em investigação, atividade fundamental para a construção de respostas mais elaboradas às questões que emergem do cotidiano da prática -, que os favoreça no planejamento, indicação e realização de estratégias profissionais que rompam com práticas conservadoras, burocráticas, imediatistas e que consigam se articular, de fato, aos interesses dos trabalhadores e trabalhadoras - compreendendo o quão complexo é a construção de um exercício profissional nessa direção e o tempo que se leva para tal.

Uma questão candente que se põe neste contexto é que se não é da produção de conhecimento da área de Serviço Social que os assistentes sociais podem esperar uma produção qualificada que oriente os assistentes sociais na direção do projeto profissional, de qual produção e de qual área de conhecimento eles podem esperar uma produção que os ilumine nessa direção?

Quando Coutinho afirma que a produção de conhecimento na perspectiva dos interesses dos trabalhadores "só terá um papel social quando as ideias do marxismo chegarem às grandes massas", ele está trazendo para a nossa realidade, as afirmações de Marx de que o conhecimento quando penetra as massas se torna força material. E o conhecimento não chega nem aos pequenos e grandes intelectuais e nem às massas de forma mágica e muito menos por osmose. De ambos os lados, há que se fazer escolhas entre conteúdos e formas, o que exige muito investimento, sacrifício. Não é sem razão que como lembra Coutinho, "Gramsci dizia que é mais importante difundir entre as massas uma ideia correta já conhecida pelos intelectuais do que um intelectual isolado criar uma ideia nova que se torne monopólio de um grupo restrito" e, diria eu, ou democratizar um conhecimento apropriado de forma equivocada e/ou o conhecimento conservador; as duas formas se prestam a servir o capital. "A socialização do conhecimento, sobretudo do conhecimento ligado ao pensamento social, é uma tarefa fundamental para os intelectuais", que 
não o fazemos, diria eu, não tanto por "vaidade", mas porque este é um processo altamente exigente e que realmente nos coloca "nus" frente aos trabalhadores. (Vasconcelos, 2015, p.250)

Ora, aqui estamos nos referindo à democratização do conhecimento produzido com uma massa de assistentes sociais que cada vez mais se encontra pressionada por condições de vida, de formação em todos os níveis - o que exige mediações complexas entre a totalidade social e as questões singulares que no cotidiano profissional se mostram, de maneira fragmentada - e condições degradantes de trabalho que coloca empecilhos para alçar a uma condição intelectual que os favoreça na apropriação das complexas reflexões produzidas pela categoria que, se já não são acessadas com facilidade por docentes/pesquisadores da categoria e das demais áreas afins, coloca-se para a massa da categoria como uma língua estranha, na medida em que, no que se refere à profissão, se resumem a um dever ser abstrato, sem base na realidade em movimento.

No capitalismo, especialmente neste momento histórico de crise estrutural do capital, desemprego estrutural e destruição ambiental - o que favorece pandemias como a covid-19 -, os diferentes segmentos da classe trabalhadora vivenciam um aumento brutal da precariedade das condições de vida e de trabalho e da destruição total dos parcos espaços de participação democrática, apartando-os cada vez mais do acesso à educação, à saúde, ao trabalho, à cultura etc., o que repercute na própria categoria dos assistentes sociais como parte e expressão desta classe. Especialmente neste momento histórico, é que o acesso a uma produção de conhecimento qualificada e comprometida com uma intervenção consciente anticapitalista é urgente.

\section{Referências}

ABEPSS. Diretrizes gerais para o curso de serviço social (com base no Currículo Mínimo aprovado em Assembleia Geral Extraordinária de 8 de novembro de 1996). Net, jun. 2020. Disponível em: $<$ http://www.abepss.org.br/arquivos/textos/documento_201603311138166377210.pdf>. Acesso em: 26 jun. 2020
ALQUERQUE, Tamires da Silva. Serviço Social, Projeto Profissional e Pro- dução de Conhecimento: a Revista Serviço Social \& Sociedade/2010-2014 (Trabalho de Conclusão de Curso). Universidade do Estado do Rio de Janeiro, Rio de Janeiro, 2015. 
BALTAR, Juliana Ferreira. Serviço Social, Projeto Ético Político e Produção de Conhecimento: o $13^{\circ}$ CBAS (Congresso Brasileiro de Assistentes Sociais): uma análise comparativa entre os dois últimos CBAS (Trabalho de Conclusão de curso). - Universidade do Estado do Rio de Janeiro, Rio de Janeiro, 2012.

BORGES, Marianna Amendola. Serviço Social, Produção de Conhecimento e Projeto Ético-Político da Profissão: a análise dos trabalhos apresentados no XII. Encontro Nacional de Pesquisadores em Serviço Social - ENPESS/ 2010 (Trabalho de Conclusão de Curso). Universidade do Estado do Rio de Janeiro, Rio de Janeiro, 2013.

COUTINHO, Carlos Nelson. Intervenções. O marxismo na batalha das ideias. São Paulo: Cortez, 2006.

DORIA, Thamaris. Serviço Social, produção de conhecimento e projeto éticopolítico. Artigos publicados na Revista Katálysis- 2012-2016. (Trabalho de Conclusão de Curso). Universidade do Estado do Rio de Janeiro, Rio de Janeiro, 2017

IAMAMOTO, Marilda Vilella. Serviço Social em tempo de capital fetiche: capital financeiro, trabalho e questão social. - 5. ed. São Paulo: Cortez, 2007. - As dimensões ético-políticas e teórico-metodológicas no Serviço Social contemporâneo. In: MOTA, Ana Elizabete et al. (org.). Serviço Social e Saúde: formação e trabalho profissional. 3.ed. São Paulo: Cortez, 2008.

LIMA, Renata Cristina Mendes. O Projeto Ético-Político do Serviço Social e a produção de conhecimento dos assistentes sociais no $12^{\circ} \mathrm{CBAS}$.(Trabalho de Conclusão de Curso) Universidade do Estado do Rio de Janeiro, Rio de Janeiro, 2010.

MIRANDA, Mariana Cordeiro. Serviço Social e pesquisa: uma relação indissociável. Análise do 'Currículo Lattes' dos Bolsistas de Produtividade-CNPq/ Serviço Social (Trabalho de Conclusão de Curso). Universidade do Estado do Rio de Janeiro, Rio de Janeiro, 2011.

NERI, Vitória Monteiro. A produção de Conhecimento como parte constitutiva do Projeto Ético-Político do Serviço Social brasileiro. Análises dos artigos publicados na revista de Serviço Social: Em Pauta entre os anos 2007-2014 (Trabalho de Conclusão de curso). Universidade do Estado do Rio de Janeiro, Rio de Janeiro, 2016. 
NETTO, José Paulo. O Serviço Social e a tradição marxista. Serviço Social \& Sociedade, São Paulo, n.30, p. 89-102, 1989.

. Notas para a discussão e sistematização da prática e teoria em Serviço Social: metodologia no Serviço Social. Cadernos Abess, São Paulo, Cortez, n. 3, p. 141-161, 1989.

. Introdução ao método da teoria social. In: Serviço Social: direitos sociais e competências profissionais - Brasília: CFESS/ABEPSS - v. 1, 2009, p. 667-700.

RODRIGUES, Natália C. Faro. Produção de Conhecimento, Projeto éticopolítico e contribuições para a prática no Serviço Social. Artigos publicados na Revista Temporalis/ABEPSS (2010-2015) (Trabalho de Conclusão de Curso). Universidade do Estado do Rio de Janeiro, Rio de Janeiro, 2015.

SILVA, Luciana da Conceição e. Produção de Conhecimento no Serviço Social $12^{\circ}$ e $13^{\circ}$ CBAS: Projeto ético-político e exercício Profissional (Trabalho de Conclusão de Curso). Universidade do Estado do Rio de Janeiro, Rio de Janeiro, 2013.

SILVA, Mayana de Souza Gomes da. Serviço Social, Projeto Ético-Político da Profissão e a Produção do Conhecimento no Encontro Nacional de Pesquisadores em Serviço Social-ENPESS 2008. (Trabalho de Conclusão de Curso). Universidade do Estado do Rio de Janeiro, Rio de Janeiro, 2010. VASCONCELOS, Ana Maria. de. A prática do Serviço Social: cotidiano e práticas democráticas - Projeto de Pesquisa. Rio de Janeiro: UERJ, 2000.

A Prática do Serviço Social. Cotidiano, formação e alternativas na área da saúde. 6. ed. - São Paulo: Cortez, 2002.

A Assessoria como Processo Constitutivo de Práticas Mediadas pelos Princípios do SUS e do Projeto Ético-Político do Serviço Social Brasileiro. In: III CONGRESO NACIONAL DE TRABAJO SOCIAL, 2011, Tandil, Argentina, Anais... Tandil, Argentina, 2011. (CD-ROM).

. Serviço Social e Projeto Ético Político. Anais do ENPESS (2008-2010) e CBAS (2007-2010). In: XIV CONGRESSO BRASILEIRO DE ASSISTENTES SOCIAIS,. 2013, Águas de Lindoia, Anais.... Águas de Lindoia, 2013 (CD-ROM).

A/O Assistente Social na luta de classes. Projeto Profissional e mediações teórico-práticas.1. ed. São Paulo: Cortez, 2015. 
. (e outros). Projeto Ético-Político do Serviço Social e Formação Profissional na FSS/UERJ. In: III Congreso Nacional de Trabajo Social, 2011, Tandil, Argentina, Anais....Tandil, Argentina, 2011. (CD-ROM).

et al. Produção de Conhecimento nos Eventos do Serviço Social: Uma Análise acerca das comunicações socializadas nos anais do ENPESS e CBAS. In: I CONGRESSO ESTADUAL DE ASSISTENTES SOCIAIS DO ESTADO DO RIO DE JANEIRO, 2013, Rio de Janeiro, Anais.... Rio de Janeiro, 2013 (CD-ROM). 